\section{P3.206 KNOWLEDGE OF HUMAN PAPILLOMAVIRUS AND ITS PREVENTION AMONG UNIVERSITY STUDENTS IN RIO DE JANEIRO, BRAZIL}

${ }^{1}$ Silvia Maria Baeta Cavalcanti, ${ }^{2}$ Aimée Denzeler Baptista, ${ }^{2}$ Carolina Xavier Simão, ${ }^{2}$ Helena Dutra Campos, ${ }^{2}$ Vitória Carvalho Guimarães Dos Santos, Juliana Gil Melgaço, ${ }^{2}$ Claudia Lamarca Vitral. 'Universidade Federal Fluminense, Niteroi - RJ, Brazil; ${ }^{2}$ Universidade Federal Fluminense, Niterói - RJ, Brazil; ${ }^{3}$ Fiocruz, Niterói - RJ, Brazil

\subsection{6/sextrans-2017-053264.441}

Introduction Human papillomavirus (HPV) infection is the most prevalent sexually transmitted virus in the world. One of the barriers to the implementation of prevention programs against the disease is the limited knowledge possessed by most populations regarding the virus and its possible consequences. Methods A total of 473 students aged 18 to 78 years (mean $28.2 \pm 9.35)$ from two public universities from Rio de Janeiro State attending different undergraduate courses from health and non-health area, answered a questionnaire about transmission, clinical features and the possible consequences of persistent HPV infection. The questionnaire was self-applied under the supervision of the authors.

Results Although most of the students independent of the study area had already heard of HPV $(99.3 \%$ from health and 92.2\% non-health courses), a significant portion did not associate virus infection with the appearance of warts in the genital tract $(40,3 \%$ from health and $62.7 \%$ from non-health courses). Among female students enrolled in non-health courses, $61.1 \%$ did not recognise cervical cancer as a possible consequence of HPV infection. Considering the knowledge of risk situations as a basic form of prevention of HPV infection, only $33.2 \%$ of the students from non-health courses identified 3 or 4 of the four HPV infection risk situations presented in the questionnaire. Even the use of condoms, a basic STD prevention attitude, was not recognised by $13 \%$ of the students interviewed regardless of the attending course. At the end of the interview all participants received an informative folder on the issues investigated.

Conclusion Results highlight the need for educational campaigns regarding HPV infection, its potential as a cervical cancer agent and the forms of prevention available among university students.

\section{P3.207 HUMAN PAPILLOMAVIRUS INFECTION IN ORAL AND ANOGENITAL SITES: PREVALENCE AND RATES OF CONCORDANCE}

Silvia Maria Baeta Cavalcanti, Thaissa Isaias Cordeiro, Fernanda Nahoum Carestiato, Willker Menezes da Rocha, Daniele Ceperuelo Lisboa, Raquel da Hora Barbosa, Mauro Romero Leal Passos, Tegnus Depes De Gouvea. Universidade Federal Fluminense, Niteroi - RJ, Brazil

\subsection{6/sextrans-2017-053264.442}

Introduction HPV infection causes cancer at several anatomical sites. However, the natural history of the infection in non-cervical sites have been understudied, especially at the oral epithelium.

Methods In our study, we investigated 351 samples from three different sites of 117 patients, searching for HPV By generic and specific PCR and Microarray, and related risk factors.

Results HPV DNA prevalence was $89.5 \%$ (105/117) in the genital lesions, 53.8\% (63/117) in oral samples and 59\% (69/ 117 ) in anal samples. Regarding the risk factors associated with HPV in the genital lesions, we found statistically significant rates for oral $(\mathrm{p}=0.039)$ and anal sex practices $(\mathrm{p}=0.0000012)$. For oral samples, we observed a relevant correlation concerning oral contraceptive use $(p=0.039)$, tobacco smoking $(p=0.036)$ and alcohol use $(p=0.0075)$ while in anal samples, we found higher risk for HPV infection in patients relating non-exclusive sexual partners $(p=0.013)$. The presence of viral DNA in all the three sites was observed in $36.8 \%$ of the cases (43/117). Among them, 18\% (21/117) presented concordant HPV genotypes, diverging from the literature, corroborating that there is still much to learn about HPV natural history, since different biological behaviours are expected within different populations.

Conclusion In our study we also evaluated if the detection of oral HPV would suggest an infection in the anogenital tract. Nevertheless, our results showed only $36.8 \%$ of correlation pointing out that it is not suitable as a an auxiliary biomarker for HPV anogenital infections.

\section{P3.208 THE INFECTION WITH HUMAN PAPILLOMAVIRUS (HPV) TYPE 16 FEATURES GREATER CHANCE TO P16INK4A GENE METHYLATION IN CERVICAL LESIONS COMPARED TO OTHER VIRAL TYPES}

Silvia Maria Baeta Cavalcanti, Willker Menezes da Rocha, Raquel Da Hora Barbosa, Larissa Alves Afonso, Kátia Cristina da Silva, Gutemberg Almeida, Mauro Romero Leal Passos, Silvia Maria Baeta Cavalcanti. Universidade Federal Fluminense, Niteroi - RJ, Brazil

\subsection{6/sextrans-2017-053264.443}

Introduction Studies have shown that persistent infection by high risk human papillomavirus (HR-HPV), especially type 16, is responsible for cervical cancer development. For the development of a malignant phenotype, several mechanisms are involved, among them the process of epigenetic DNA methylation, which results in gene silencing, leading to abrogation of cell cycle control, escape from senescence, and induction of proliferation, that therefore can collaborate in carcinogenesis. Understanding how the epidemiological factors can influence the mechanism of methylation related to infection of the HRHPV is an unclear situation to be unveiled. The objective of this study was to evaluate the infections caused by HPV16 in patients attended at Gynaecology Institute, of UFRJ, in the period between 2012 and 2013, considering aspects of methylation in host gene $\mathrm{p}^{\text {INK4a }}$.

Methods The cervical smears were submitted to the detection of HPV DNA by Polimerase Chain Reaction (PCR) using primers MY09/11, genotyped with primers for the E6 gene of HPV16, evaluated the methylation of the host pINK4a gene by Nested-MSP technique, and collected epidemiological data, which included socio-demographic and behavioural factors of each patient; and, the data of the diagnostic test that served as reference, the cytopathology.

Results Our results showed nearly $76 \%$ of the studied samples presented some degree of gene $\mathrm{p}^{\mathrm{INK} 4 \mathrm{a}}$ methylated, while $24 \%$ were unmethylated. The results showed statistical significance for the correlation of the cytopathology with sexarca $(\mathrm{p}=0.05657)$, smoking $(\mathrm{p}=0.0317)$, pregnancies $(\mathrm{p}=5938 \mathrm{e}-05)$, parity $(p=0.004425)$ and number of partners $(p=0.0242)$. The p16 gene methylation correlations that showed statistical significance were pregnancy $(p=0.02725)$, parity $(p=0.01414)$, and typing $(\mathrm{p}=0.008121)$.

Conclusion We have found that the presence of HPV16 is associated with a greater chance of methylation of p16 in the lesions. Although, we also observed that the methylation of 